\title{
GESTIÓN Y ADMINISTRACIÓN DE LA COMUNICACIÓN INSTITUCIONAL EN TWITTER
}

\section{Corporate Communication on Twitter: Management and Administration}

\section{Gestão e administração da comunicação institucional no Twitter}

SALAZAR PUERTA, Soraya. Universidad Rey Juan Carlos (España), soraya.salazar@urjc.es

PRIETO DÁVILA, Pablo R. Universidad Rey Juan Carlos (España), pablo.prieto@urjc.es

Fecha de recibido: 9 de septiembre de 2014

Fecha de aceptado: 4 de noviembre de 2014

\section{RESUMEN}

El presente trabajo se centra en el uso de Twitter como medio de comunicación institucional. Muchas instituciones aún desconocen el funcionamiento de Twitter y el gran potencial que este tiene para la comunicación corporativa. Twitter permite a las instituciones aportar contenido relevante para los usuarios e iniciar conversaciones, facilitando la creación de comunidades en torno a ellas. La institución no solo ofrece información, también la recibe de la comunidad. El objetivo de este artículo es la creación de una especie de "manual” que recoja las principales premisas que debe seguir una institución para comunicarse de manera eficiente con su público objetivo en Twitter.

Palabras clave: comunicación institucional, redes sociales, manual del estilo, buenas prácticas. 


\section{ABSTRACT}

This paper focuses on the use of Twitter in institutional communication. Many institutions are still unaware of how Twitter works and the great potential that it has for corporate communication. Twitter allows institutions to provide relevant content to the users and allows starting conversations, facilitating the creation of communities. The institution not only provides information but also receives it from the community. The purpose of this paper is the creation of a "manual" on the principal premises that an institution must follow to communicate effectively on Twitter with its target audience.

Keywords: Institutional communication, social networking services, style guide, best practices.

\section{RESUMO}

O presente trabalho centra-se no uso do Twitter como meio de comunicação institucional. Muitas instituições ainda desconhecem o funcionamento do Twitter e o grande potencial que ele tem para a comunicação corporativa. O Twitter permite às instituições aportar conteúdo relevante para os usuários e iniciar conversas, facilitando a criação de comunidades em torno a elas. A instituição não só oferece informação, também recebe informação da comunidade. $\mathrm{O}$ objetivo deste artigo é a criação de uma espécie de "manual", que recolha as principais premissas que deve seguir uma instituição para se comunicar de maneira eficiente com seu público objetivo no Twitter.

Palavras-chave: comunicação institucional, redes sociais, manual do estilo, boas práticas.

\section{La importancia de la comunicación institucional}

Todas las organizaciones, para sobrevivir en su entorno, necesitan comunicarse. La principal finalidad de la comunicación es estimular a los individuos para que lleven a cabo distintos comportamientos.

Para Garrido (2008, p. 58), la falta de comunicación va en contra de la naturaleza móvil y transformadora de las instituciones. La sola idea de que su sistema sufra de inmovilidad es un fracaso.

En este sentido, la organización debe ser un centro activo difusor y receptor de información. Según Hernández Mogollón (1991, p. 27), la organización debe emprender de manera constante acciones comunicativas tanto hacia el interior como hacia el exterior. Además, tiene que detectar señales de comportamiento, implícitas o explícitas y, a partir de estas, organizar su actuación.

Se entiende por comunicación corporativa a la que hace referencia a la comunicación que se genera y se difunde interior y exteriormente en instituciones con el objetivo de reforzar la imagen de la organización. 
Para Martín Martín (2004, p. 46-47), la comunicación corporativa es: “Creación, coordinación, análisis, desarrollo, difusión y control de toda acción de gestión informativa interna y externa que diariamente se produce en una empresa o corporación, tanto a nivel de actividades, servicios y productos, que afecta a un determinado público o colectivo social y que se transmite a través de los medios de comunicación internos ${ }^{1}$ y externos ${ }^{2}$ para así potenciar su imagen corporativa".

Y para Carracosa (1992, p. 34-35) es: "El conjunto de acciones y medios que facilitan las relaciones internas y externas de una organización, de una empresa. El marco que encuadra y coordina la publicidad, el marketing y la comunicación interna y externa de una empresa o institución".

La personalidad corporativa o institucional es entendida como el posicionamiento estratégico de la organización, es decir, el conjunto de los valores y la identidad de la organización que se proyecta tanto al público externo como al interno.

El plan de comunicación debe apoyarse en el perfecto conocimiento de la acción comunicativa y debe reflejar la identidad, la cultura y las actividades de la organización.

Fernández Fernández (2011, p. 180) defiende que la gestión eficaz de la comunicación externa requiere:

1. Adaptación al funcionamiento de medios de comunicación.

2. Ajustarse a los criterios noticiosos y publicitarios para emitir mensajes que sean bien recibidos.

3. Conocimiento de la planificación de medios publicitarios y de audiencias, para buscar la máxima eficacia de las acciones.

4. Adecuada selección de los públicos para dirigirse a los sectores de mayor impacto.

La persona encargada de aplicar todas estas ideas es el responsable de la comunicación o portavoz, quien debe informar de aspectos interesantes y atractivos con el objetivo de conseguir repercusión y contribuir a la mejora de la imagen y la identidad de su marca, además de conseguir credibilidad.

\section{La comunicación institucional y las redes sociales}

Las empresas e instituciones, tradicionalmente, han utilizado los medios de comunicación de masas como vínculo con sus clientes y usuarios. Tal y como afirma Laswell (1948), citado por Mauro Wolf (1996, p. 30), en los medios de masas, "los papeles del comunicador y destinatario aparecen aislados, independientes de las relaciones sociales o situaciones culturales en las que se producen los procesos comunicativos". Se establece un vínculo en el que el emisor tiene todo el control sobre el mensaje.

Frente a la postura de Laswell, Klapper (1963, p. 247) defiende la percepción selectiva: "Los miembros del público no se presentan ante la radio, la televisión o el periódico en un estado de desnudez psicológica; están, al contrario revestidos y protegidos por predisposiciones existentes, por procesos selectivos y por otros factores". Por tanto, la interpretación individual transforma el significado del mensaje recibido pudiendo llegar hasta el extremo de cambiar el sentido del propio mensaje.

1 La comunicación interna: conjunto de acciones llevadas a cabo por la organización para la creación y mantenimiento de buenas relaciones entre los miembros de una empresa.

2 La comunicación externa: es una parte de la comunicación dirigida especialmente a los públicos externos como clientes o medios de comunicación. 
Para la teoría de los Usos y las Gratificaciones, la influencia de las comunicaciones de masas sería incomprensible si no se diese importancia a los criterios de experiencia y a los contextos situacionales del público: los mensajes son adaptados al contexto subjetivo de experiencia, conocimiento y motivaciones. Además, el uso de los medios ofrece recompensas.

Como se puede observar, el usuario ha ido ganando importancia a la hora de interpretar los mensajes en los procesos de comunicación de masas. Sin embargo, todas estas teorías parten de una comunicación lineal y unidireccional.

La implantación de las Tecnologías de la Información y la Comunicación (TIC) que usan Internet como canal de distribución está produciendo numerosos cambios en el sistema de comunicación de las instituciones con sus públicos. Según afirma Castells (2009, p. 178-187), "las redes de comunicación horizontales basadas en Internet se activan gracias a sujetos comunicativos que determinan tanto el contenido como el destino del mensaje y son al mismo tiempo emisores y receptores de mensajes multidireccionales". Se establece así, un nuevo marco tecnológico multimodal y multicanal en el que el emisor tiene que interpretar los mensajes que recibe de distintos medios de comunicación y múltiples canales integrando su propio código en la interacción con el código del mensaje originado por el emisor. Además, tiene que negociar su significado como receptor a partir de una experiencia como emisor. La aparición de la producción interactiva de significado es lo que Castell denomina "Audiencia Creativa". Con el uso de las redes sociales, las instituciones pueden comunicarse de manera más segmentada y eficaz debido a la posibilidad de elaborar mensajes específicos y canalizarlos mediante actividades concretas (Castillo Esparcia, 2008, p. 2).

En lo que respecta a los hábitos de los usuarios en Internet, el acceso a las redes sociales es la tercera actividad más realizada, por detrás de la navegación web y el correo electrónico.

Las instituciones, conscientes de la importancia de las redes sociales, han comenzado a utilizarlas para reforzar la relación con los usuarios y su identidad.

El uso y carácter de las redes sociales es muy variado. Facebook es la red social que más usuarios tiene (Fundación Orange, 2012), pero los datos de Twitter son muy positivos: en los últimos años se ha convertido en la red que más crecimiento ha tenido tanto en usuarios procedentes de empresas o instituciones como en usuarios individuales.

En resumen, el papel del receptor ha sufrido un gran cambio desde las primeras teorías de la comunicación en las que se establecía una masa pasiva de destinatarios, hasta las nuevas posturas en las que un receptor activo da sentido y adapta los mensajes según sus experiencias y motivaciones. Los nuevos medios de comunicación propiciados por Internet han dado lugar a un receptor que se convierte en emisor generando, editando y compartiendo contenidos. Las instituciones y empresas, ante la enorme influencia del receptor, deben reorganizar su estrategia de comunicación en función del cliente, de sus necesidades y expectativas. 


\section{ENSAYOS}

\section{DISERTACIONES}

Anuario electrónico de estudios en Comunicación Social

ISSN: 1856-9536

Doi: dx.doi.org/10.12804/disertaciones.01.2015.01

Volumen 8, Número 1 / Enero-Junio 2015

Versión PDF para imprimir desde

http://revistas.urosario.edu.co/index.php/disertaciones

\section{1 ¿Qué es Twitter?}

Twitter es un microblogging, nacido en 2006 en San Francisco, que permite enviar y leer mensajes de 140 caracteres (llamados tuits) de manera gratuita. Los usuarios pueden unirse a otros siguiendo sus cuentas y estableciendo una comunicación online.

A septiembre de 2014, Twitter contaba con más de 271 millones de usuarios activos al mes, además, está disponible en más de 35 idiomas $^{3}$. Entre otros beneficios, permite conectar a las instituciones con los usuarios en tiempo real construyendo relaciones de gran beneficio para ambos. Twitter se está convirtiendo en uno de los principales medios de comunicación institucional.

Gráfica 1. Usuarios activos (millones) de las principales plataformas sociales en enero de 2014

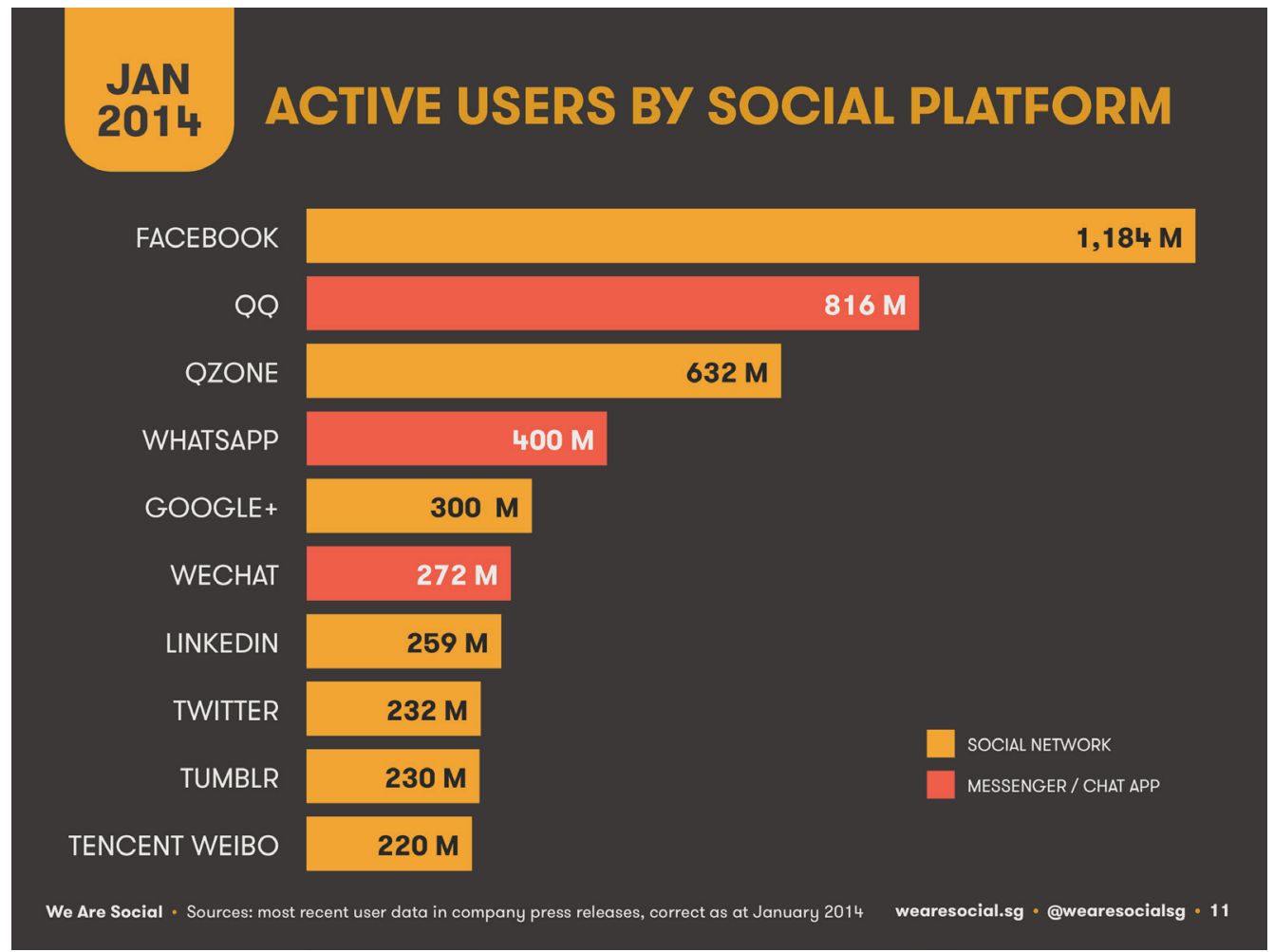

Fuente: We are social. Recuperado el 28 de septiembre de 2014, de http://wearesocial.net/ blog/2014/01/social-digital-mobile-worldwide-2014/

3 Fuente: Twitter. Recuperado el 27 de septiembre de 2014, de https://about.twitter.com/company 
Gráfica 2. Crecimiento de Twitter en usuarios mensuales activos (Monthly Active Users - MAUs) y porcentaje de crecimiento entre cuartos de año (Quarter on Quarter - Q०Q) entre el primer cuarto de 2012 y el segundo cuarto de 2014

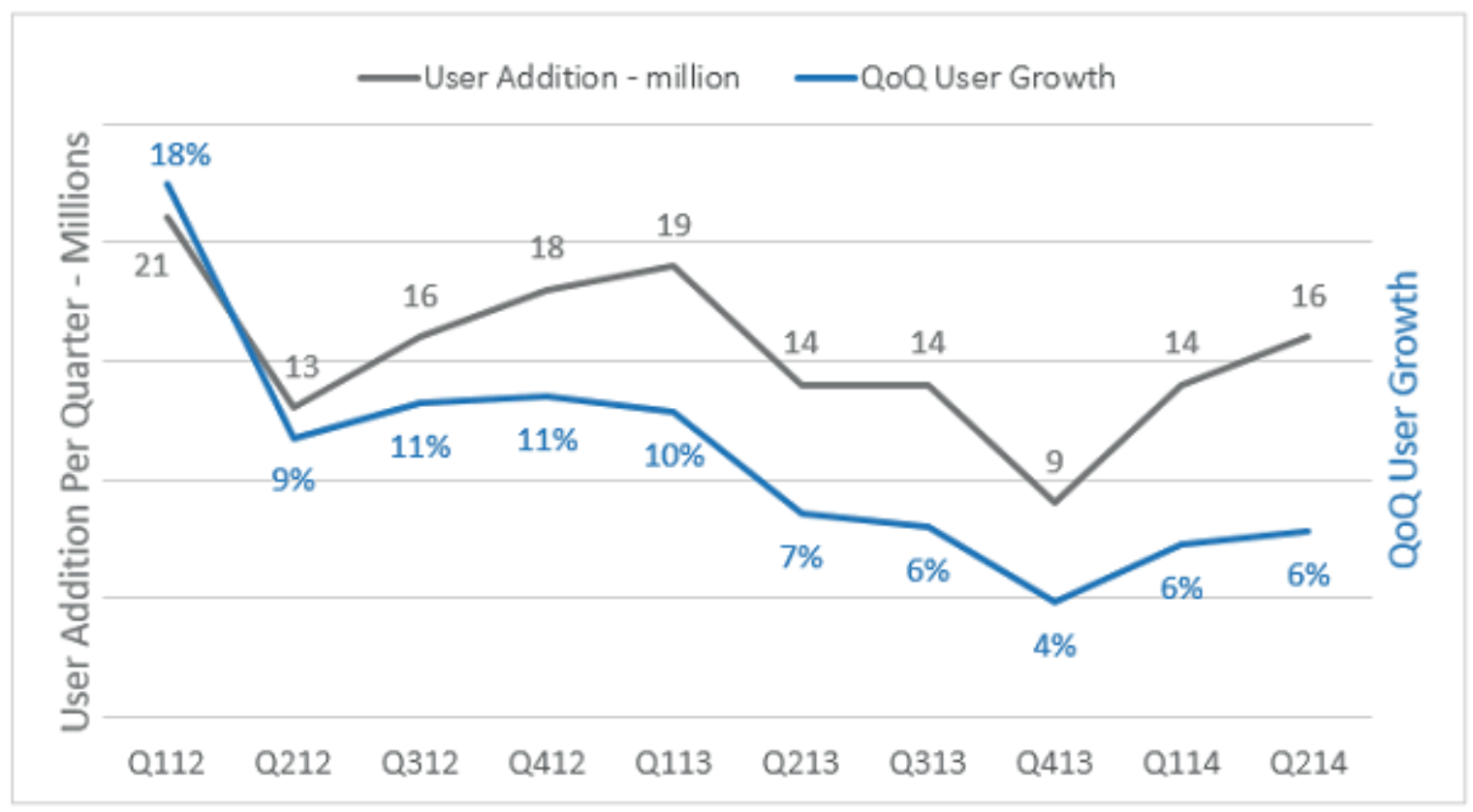

Fuente: Amigobulls.com, Technology Stock Analysis. Recuperado el 28 de septiembre de 2014, de http://amigobulls.com/articles/twitter-stock-analysis-is-user-growth-real

\section{Creación de un perfil corporativo en Twitter}

Toda institución que quiera iniciar su andadura en Twitter tiene que conocer a su público objetivo y saber si este se encuentra en Twitter. En demasiadas ocasiones, las instituciones creen, de manera errónea, que deben estar en todas las redes sociales. Sin embargo, para que la organización obtenga un beneficio real, debe estar presente únicamente allí donde esté su público objetivo.

Es un error habitual en las instituciones iniciar su andadura en Twitter de manera rápida y sin prestar demasiada importancia a la creación de su cuenta. La idea de que en Internet se puede publicar el contenido a la vez que se completa el diseño y la información de contexto, como si lo importante fuera arrancar cuanto antes, no puede aplicarse a la comunicación institucional en redes sociales.

Este primer paso, la creación de la cuenta, es esencial ya que mediante el perfil se transmite numerosa información a los seguidores. Al tratarse de un perfil institucional, el nombre será el de la organización evitando el uso de guiones, números u otros símbolos que puedan suponer un obstáculo en las búsquedas que realizan los usuarios. 
Se debe definir de manera clara a quién está dirigida cada cuenta. Gonzalo et ál. (2012) defienden que, en el caso de una gran empresa, conviene crear varias cuentas dependiendo del público al que se dirige cada una de ellas. Así, existen cuentas destinadas a los clientes, a los proveedores, a la prensa, etc.

La cuenta de Twitter está formada por un encabezado y un fondo de página. En el encabezado se ubica la imagen del perfil. Es importante elegir una fotografía que identifique a la marca, habitualmente se utilizan logos. Sin embargo, algunos autores como Gil Iberlucea (2013) defienden que en el perfil debe aparecer la fotografía de los responsables de comunicación o de los directivos ya que en Twitter la gente quiere comunicarse con personas, no con organizaciones impersonales. Lo realmente importante es que los usuarios identifiquen de manera clara con quien están hablando.

El siguiente paso es la descripción, que debe definir a la institución de manera clara e incluir palabras clave por las que los tuiteros puedan encontrar la cuenta. Es importante dejar claro, en el caso de la creación de varias cuentas en función del público, la orientación de cada cuenta (por ejemplo: atención al cliente). Es también conveniente añadir la localización de la institución, ya que en Twitter se realizan millones de búsquedas al día y una de las opciones es buscar perfiles de un área geográfica determinada.

El encabezado también permite añadir una URL, pudiendo enlazar la cuenta con la homepage o con una página especial creada para usuarios de Twitter. El fondo del encabezado debe seguir la línea corporativa. Existen dos opciones: bien utilizar algún color corporativo o uno neutro que resalte todo el encabezado.

El fondo de la página debe permitir al usuario asociar la cuenta de Twitter a una institución con solo un vistazo. En definitiva, el objetivo principal es crear una cuenta que se adapte a la identidad corporativa de la institución y sea reconocida por el usuario de manera rápida.

Es importante identificarse como cuenta oficial, lo que hará que los usuarios sean más propensos a participar. Existen dos maneras de verificar una cuenta: mediante un servicio de Twitter que se encarga de verificar cuentas o enlazando la cuenta de Twitter a la web corporativa; de esta última forma, además, hay un refuerzo mutuo entre la web y la cuenta de Twitter en cuanto a imagen institucional, visitantes y seguidores.

En resumen, cualquier institución que esté presente en Twitter debe poseer un perfil que refleje los valores, la identidad y la personalidad corporativa de la organización, de manera que sea fácilmente identificable por todos los usuarios.

\section{Plan de acción en Twitter}

Tener un plan de publicación en el que se definan los objetivos y los contenidos es esencial para llevar a cabo una comunicación efectiva. No todo es comunicable a través de las redes sociales. Por tanto, hay que acercarse a los usuarios y saber qué les interesa conocer de la institución. El contenido debe ser interesante, dinámico y cercano ya que de lo contrario se corre el riesgo de que los seguidores decidan abandonar la cuenta corporativa.

A la hora de elaborar un plan de acción se deben tener en cuenta seis puntos muy bien definidos: ¿cuáles son los objetivos?, ¿qué decir?, ¿cómo y cuándo decirlo?, ¿quién lo comunica? Y ¿cómo evaluar los resultados? 


\section{1 ¿Cuáles son los objetivos?}

El tamaño de la institución y el servicio que esta ofrece van a determinar los objetivos específicos de su plan de acción en Twitter. Sin embargo, existen una serie de aspiraciones comunes a toda organización que decide comenzar su andadura en las redes sociales. Gonzalo et ál. (2012) establecen varios objetivos generales que se deben tener en cuenta a la hora de elaborar el plan de acción:

- Ofrecer una atención mejor. Permitirá conservar a los usuarios habituales y fidelizar a otros nuevos.

- Ganar nuevos usuarios. Ofreciendo un trato personalizado.

- Fortalecer la institución. El buen trato con el usuario permite que una institución se posicione de manera positiva en la mente del lector.

- Tener un feedback continuo y reciproco. Mantener un diálogo constante con los usuarios ayudará no solo a resolver sus dudas, sino también a conocerlos.

\section{2 ¿Qué decir?}

Es esencial definir el contenido de los tuits para que el usuario conozca qué información puede encontrar en la cuenta. Se debe ofrecer contenido actual y de calidad. Los usuarios buscan información interesante que les resulte novedosa; si se ofrece información muy desfasada, los usuarios no sentirán la necesidad de seguir la cuenta.

Es importante crear atracción, es decir, buscar temas interesantes que satisfagan las necesidades de los usuarios. Una buena opción es la utilización de imágenes y videos que resulten atractivos a un seguidor que en muchos casos está cansado del uso del texto y busca algo más.

El mensaje enviado debe ser concreto y preciso, ya que existe un espacio limitado de 140 caracteres. Para ampliar la información se puede incluir un enlace con otra web4.

El número de mensajes publicados en Twitter es tan elevado que si se quiere lograr una comunicación efectiva es necesario utilizar palabras claves que se convertirán en etiquetas o hashtags y permitirán crear canales de conversación para que los seguidores puedan unirse y seguir las discusiones. Los hashtags deben ser una palabra o una cadena de palabras cortas por la limitación de caracteres.

\section{3 ¿Cómo decirlo?}

Tan importante es el contenido de los tuits como la forma. No se debe olvidar que las redes sociales suponen un espacio interactivo, pero cada una de ellas tiene sus limitaciones.

Cuando se escribe un tuit se debe ser claro y conciso. La agencia consultora Territorio Creativo (2011) establece una serie de pautas para la redacción en Twitter.

- La información debe ser interesante.

- Se deben incluir hashtags para indexar la conversación.

- Hay que limitar los mensajes a 110 caracteres para que otros usuarios puedan retuitear y añadir información hasta los 140.

4 Una herramienta muy útil es Bit.ly que acorta las direcciones de Internet de manera que se puedan incluir en un tuit. 
- Para adquirir mayor notoriedad, es útil invitar a los seguidores a participar con un "por favor, RT" o crear hashtags como "\#pasalo" o "\#recomendar".

- Anunciar las novedades.

- Usar un lenguaje claro, sencillo y comprensible de manera que muestre proximidad y cercanía con el usuario, evitando abreviaciones poco conocidas.

- Usar oraciones completas (sujeto, verbo y predicado) y signos de puntuación.

- Evitar connotaciones negativas, lenguaje coloquial y malsonante y referencias propias constantes.

- No abusar de los tuits en inglés en el caso de que los seguidores sean hispanohablantes.

- Retuitear y aportar respuestas sobre los tuits de otros usuarios.

- Procurar remitir siempre a la fuente oficial de la información y confirmar la veracidad de los retuits.

Es importante el tono y el estilo que la institución utiliza para comunicarse. Es recomendable utilizar un tono neutro que se desvincule de ciertos intereses. La institución debe mostrarse con claridad y transparencia evitando la polémica. El lenguaje debe ser sencillo y comprensible de manera que muestre proximidad y cercanía con el usuario, pero se deben evitar expresiones demasiado coloquiales o malsonantes.

\section{4 ¿Cuándo decirlo?}

A la hora de gestionar su cuenta, las instituciones deben ser constantes y mantener una relación continua con sus potenciales usuarios. Para ofrecer información de manera regular, es conveniente fijar un número mínimo de tuits en un intervalo de tiempo.

El timeline debe ser dinámico. Para ello, se debe aportar información de valor que garantice la presencia continua de seguidores.

No es conveniente publicar todos los tuits a la vez, ya que se corre el riesgo de saturar a los seguidores. Se deben tener en cuenta los hábitos de ellos y sus horas de lectura para aumentar el tráfico de información. Para esto, se puede observar la actividad de los usuarios en Twitter, ver en qué horarios publican o retuitean nuestro contenido. Si se logra sintonizar con los hábitos de conexión de los usuarios -en qué horas, lugares y medios (móvil, ordenador, etc.)-, tendremos garantizada la penetración de la información en la mente de los seguidores.

Territorio Creativo (2011) defiende que las instituciones tienen una alta probabilidad de lectura si centran su actividad al inicio de la mañana, momento tradicional de lectura; antes de comer, cuando se suele hacer un repaso de lo acontecido, y por la tarde, antes de acabar la jornada laboral.

\section{5 ¿Quién comunica?}

Twitter se ha impuesto como uno de los espacios más importantes que permiten a las instituciones entablar conversaciones y aportar contenido interesante a los usuarios. Pero para que esta situación llegue a producirse es necesario el trabajo de una persona con formación que vele por la importancia de la reputación online, que cree contenido de valor y que actúe de manera transparente estableciendo una buena relación entre los usuarios y la institución.

Vargas (2011) asegura que uno de los principales errores que cometen las instituciones es entender Twitter como un "depósito de links", en el que cualquier persona está facultada para manejar una cuenta corporativa. Esta 
concepción de Twitter provoca que a menudo se recurra a personas sin preparación que pueden provocar una autentica crisis.

La gran competencia existente en Internet exige un profundo conocimiento de las plataformas interactivas y de las relaciones que se establecen en ellas. Por tanto, se debe recurrir a un profesional de la comunicación que gestione de manera eficaz la cuenta corporativa de Twitter.

A medida que las TIC se han ido asentando, va cobrando importancia la figura del Community Manager, el encargado de "conversar con la audiencia, escuchar y distribuir contenidos de la organización en los medios sociales" (Castelló Martínez 2010, p. 11).

\section{6 ¿Cómo evaluar los resultados?}

A la hora de elaborar el plan de acción, es conveniente fijar unos objetivos realistas y concretos. De esta forma, su medición y evaluación será más fiable y fácil. Las instituciones, en numerosas ocasiones, miden su éxito según el número de seguidores; este es un error muy común. Lo que realmente debe interesar a las organizaciones no es la cantitad total de seguidores, sino el número de seguidores activos o seguidores referentes en una materia.

Como afirma Lázaro Ávila (2012): "El volumen de seguidores es una cifra interesante, pero no determinante: lo importante es la relevancia y la facultad de influir en la comunidad... en definitiva, la capacidad de engagement y amplificación del mensaje".

Gil Iberlucea (2013) establece una serie de factores que ayudan a comprobar la repercusión de una marca en los usuarios de Twitter: el número de tuits, las menciones, los clics, los retuits, los leads y los replies.

- Tuits. El número de tuits o mensajes que la institución genera es un aspecto esencial ya que si la cuenta corporativa de Twitter no es activa, no se conseguirá que exista una fuerte repercusión en los usuarios.

- Menciones. Se trata del número de veces que los usuarios citan o dirigen un mensaje a la institución.

- Clics. La curiosidad que despiertan los tuits que incluyen enlaces se puede comprobar mediante el número de clics que los usuarios hacen en los enlaces. De esta forma, podemos medir el tráfico que genera desde la cuenta de Twitter hacia otras páginas web.

- Retuits. Un retuit permite dar notoriedad a un tuit de otro usuario. Este aparece en la cronología del usuario que retuitea y puede ser visto por todos sus seguidores de manera que si la institución recibe muchos retuits, estará creando contenido interesante para sus seguidores y ampliando su difusión.

- Leads. Cantidad de potenciales usuarios que se capturan desde Twitter y se interesan por la página web corporativa de una institución.

- Replies. Las respuestas que se generan a partir de un tuit.

Gámez (2013) añade otra métrica: el número de listas en las que aparece la cuenta de una institución. El estar incluido dentro de una lista demuestra que las aportaciones son interesantes para el usuario que creó la lista; es un reconocimiento a la creación de valor en Twitter.

Vaughan (2012) establece un nuevo aspecto relevante a la hora de medir la popularidad en Twitter, los hashtags. Es muy recomendable la creación de hashtags por parte de las instituciones porque su seguimiento permite medir cuantas veces se ha utilizado y, por tanto, la repercusión del tema planteado. 
También es necesario conocer las herramientas más relevantes para el diagnóstico de la reputación de una institución en el microblogging. Son numerosos los programas creados específicamente para controlar el tráfico en Twitter, pero los más destacados son: Twitter Counter, Twitter Analytics, Twitalyzer, Klout, Twitter Stats, Twitter Search, Twitter Friends y Google Analytics.

- Twitter Counter. Herramienta que permite contabilizar los seguidores, cuántas personas retuitean la cuenta de la empresa y cuántas la mencionan. También permite analizar a la competencia. http:// twittercounter.com/

- Twitter Analytics. Herramienta oficial de Twitter que proporciona datos y estadísticas sobre el tráfico de una cuenta. https://analytics.twitter.com/

- Twitalyzer. Esta herramienta mide la influencia en Twitter y establece una comparación en relación a los datos de la última consulta. http://twitalyzer.com/

- Klout. Servicio gratuito que mide la influencia de una cuenta en Twitter. Klout asigna una puntuación de 1 a 100 basada en tres parámetros: el verdadero alcance, la probabilidad de amplificación y la puntuación de la red. http://klout.com/

- Twitter Stats. Ofrece datos estadísticos sobre los tuits, estableciendo la media mensual y diaria, y estudiando las horas en las que la cuenta se ha mantenido más activa. http://www.tweetstats.com/

- Twitter Search. Permite conocer qué dicen los usuarios sobre una marca. Es una herramienta muy útil que detecta todo lo que se habla en Twitter sobre una empresa sin necesidad de que los usuarios la mencionen o sigan el hashstag creado por ella. https://twitter.com/search-home

- Twitter Friends. Ayuda a conocer qué tipo de usuario se es en Twitter. De esta manera, se detectan cuáles son las debilidades de cada empresa al gestionar la cuenta. http://stats.brandtweet.com/

- Google Analytics. Es un servicio muy útil para las compañías, destinado a analizar quiénes son y desde dónde provienen las personas que hacen clic en los enlaces y que llegan hasta las páginas web. De esta forma, se puede detectar el número de usuarios de la web corporativa que proceden de Twitter. http:// www.google.com/analytics/

En resumen, toda institución que quiera lograr una comunicación efectiva en Twitter debe elaborar un plan de comunicación en el que se definan los objetivos y las acciones de comunicación que se llevarán a cabo. Este plan de comunicación debe contemplar los siguientes puntos: ¿cuáles son los objetivos? (Qué es lo se quiere lograr en Twitter), ¿qué se va a decir? (Con contenido actual, de calidad e interesante para los seguidores), ¿cómo lo van a decir? (Tono neutro, claro y sencillo), ¿cuándo lo van a decir? (Publicación asidua y teniendo en cuenta los hábitos de conexión de los usuarios), ¿quién lo va a decir? (Publicado por profesionales que posean un profundo conocimiento de las TIC) y ¿cómo medir el impacto? (Medición y evaluación en función de los objetivos).

\section{5. ¿Cómo gestionar una cuenta institucional en Twitter?}

Las redes sociales nacidas bajo Internet comparten muchas similitudes con las redes o contactos que se pueden establecer en el día a día. Cada usuario, como en la vida real, posee una identidad única y muy variada, aunque en las redes sociales la mayoría de los usuarios suelen comportarse bajo unos patrones bastante similares. Por ello, si se quiere conectar con el público objetivo, se debe saber qué es lo que los usuarios esperan de la institución. 
Twitter, a través de su web, adelanta algunas de las claves que las instituciones deben emplear para comunicarse de manera eficaz:

1. Saber escuchar a los usuarios. Los comentarios pueden ayudar a conocer cuál es la percepción y reputación de la institución, y así poder actuar sobre esta base.

2. Encontrar tu voz. Es interesante establecer una identidad propia en Twitter. Para ello, es necesario aportar valor a los tuits y potenciar la conversación contestando a todas las preguntas que se planteen.

3. Trabajar sobre la base de una estrategia. En Twitter todo sucede en tiempo real, pero las acciones deben ser cuidadas y planificadas con antelación.

4. Expandir tus ideas, propiciando que los seguidores hablen de la institución.

Álvarez Marañón et ál. (2011) establecen varios consejos que las instituciones deben seguir para mejorar su influencia en Twitter:

1. Ser generoso. Se debe retuitear a menudo contenido ajeno. Así estaremos afirmando que nos interesa el contenido de otros tuiteros.

2. Tuitear con frecuencia. Cuanto más se tuitea, existe mayor oportunidad de darse a conocer.

3. Rodearse de gente influyente. La calidad de los seguidores es muy importante: es preferible un grupo pequeño de seguidores influyentes que un gran grupo que tenga un impacto reducido.

4. Entablar conversación. Un usuario que genere conversación mantendrá una relación más cercana con sus seguidores y podrá atraer a nuevos seguidores. Una buena opción es hacer preguntas generando debates sobre temas de interés que creen una audiencia activa.

Territorio Creativo (2011) añade algunas pautas que pueden ayudar a relacionarse de forma eficiente con los usuarios. En primer lugar, detectar a qué seguidores es interesante seguir en relación a un tema concreto; así, se da valor a los seguidores. En segundo lugar, es imprescindible seguir a quien nos sigue; solo así podremos crear una comunidad e intercambiar mensajes privados con los seguidores. En tercer lugar, se debe seguir a gente influyente que, a su vez, pueda seguir a la institución.

Siempre que una persona decida seguir una cuenta corporativa, es interesante darle la bienvenida mediante un mensaje cercano que puede ser generado, de manera automática, con herramientas como SocialOomph 5 .

Gonzalo et ál. (2012) apunta una serie de acciones complementarias que las empresas deben desarrollar para que sus cuentas de Twitter adquieran notoriedad.

1. Vender con descuentos. Para ello, se deben publicar las ofertas en tuits de manera que los seguidores sean los primeros en conocer las promociones teniendo recompensas por seguirte.

2. Dar un descuento a cada nuevo seguidor.

3. Dar premios sorpresa. Es conveniente generar tráfico dentro de la cuenta. Por ello, una buena acción es organizar concursos que potencien la participación de los usuarios a cambio de una recompensa.

4. Hacer lanzamientos o promociones. Publicitar nuevos productos a través de Twitter aportando información útil y atractiva para los usuarios. Una herramienta muy recomendable para los eventos es Twtvite ${ }^{6}$, que permite gestionar distintos eventos creando encuestas, listas de invitados, etc.

5 https://www.socialoomph.com/

6 http://twtvite.com/. La web oficial de Twtvite posibilita la creación de eventos y los seguidores pueden confirmar su asistencia a través de Twitter de manera que la empresa tenga una lista definitiva de la gente que asistirá al evento. 
5. Crear una campaña de intriga. Twitter permite que la información se difunda de manera muy rápida, creando expectación entre los usuarios.

A la hora de gestionar una cuenta corporativa de Twitter, es necesario utilizar herramientas que permitan automatizar funciones y aportar valor a los usuarios. Una de las herramientas más populares para la gestión de redes es Hootsuite ${ }^{7}$, que permite gestionar varias cuentas de Twitter al mismo tiempo. Resulta una opción muy interesante si la institución tiene varias cuentas destinadas a distintos públicos. Además, permite hacer un seguimiento de todo lo que ocurre en Twitter. Estructurado gráficamente en columnas, a través de Hootsuite, es posible escribir tuits, subir fotos y video, insertar enlaces, en definitiva, mantener conversación con nuestros seguidores. Otra de sus grandes ventajas es que permite programar y automatizar los tuits a lo largo de un tiempo. Herramientas similares a Hootsuite son Buffer o Sendible.

Aunque son muchas y diversas las reglas que deben tenerse en cuenta, la esencia de todas ellas puede resumirse en fomentar la conversación y adecuar la actuación de las instituciones a lo que los usuarios esperan de ellas.

\section{Visibilidad en Twitter}

Según los propios datos de Twitter, el microblogging cuenta con 302 millones de usuarios activos al mes que generan una media de 500 millones de mensajes al día.

La promoción de cuentas y tuits en Twitter se realiza mediante "TwitterAds". El microblogging oferta tres maneras distintas de publicitarse: mediante cuentas, tuits y temas promovidos.

- Cuentas promovidas (Promoted Acccounts). Se anuncia una determinada cuenta a ciertos usuarios, en función de sus intereses. La cuenta promovida aparece en el apartado "A quién seguir", señalada por una fecha amarilla. Su principal objetivo es incrementar el número de usuarios. Su funcionamiento es sencillo: el algoritmo de Twitter analiza los seguidores de la cuenta a promocionar e identifica qué otros perfiles similares sigue. A continuación, analiza los seguidores de estas cuentas similares. Si estos usuarios no siguen a la cuenta promocionada, les hará una recomendación de seguimiento.

- Tweets promovidos (Promoted Tweets). Este tipo de tuits sirven para ganar notoriedad. Permite hacer una segmentación de los usuarios en función de distintos criterios como pueden ser la localización geográfica, los términos de búsqueda o el perfil. Se distinguen de los tuits normales porque aparecen en amarillo y llevan escrito "promocionado", aparecen al principio de la lista de resultados cuando se realiza una búsqueda y en el timeline de los usuarios. Son visibles en Twitter.com, en distintas aplicaciones y en Twitter para móviles.

- Temas promovidos (Promoted Trends). Se utiliza para resaltar un tema, aumentando la conversación en torno a este. Aparecen en la primera posición de los "Temas del Momento" y se distinguen porque llevan escrito la palabra "promocionado". Son solo visibles en Twitter.com.

En cuanto a las tarifas, Twitter explica en su página oficial que las organizaciones que deseen promocionarse en este microblogging pagarán cuando los usuarios sigan la cuenta promovida, respondan o hagan clic en los tuits, es decir, la empresa pagará dependiendo de la interacción que el usuario tenga con el elemento promovido. En el caso de los temas promocionados, existe una tarifa fija. Sin embargo, en los tuits y cuentas promovidas el precio

7 http://hootsuite.com/ 
se fija mediante subasta. Twitter permite a las organizaciones establecer un presupuesto máximo diario. Cuando el número de clics o de seguidores haya alcanzado ese presupuesto, los anuncios se dejan de mostrar automáticamente.

\section{Conclusiones}

Se puede concluir que:

1. La gestión de la comunicación institucional no es una actividad profesional nueva en las organizaciones. Sin embargo, la llegada primero de la Web 2.0 y posteriormente de las redes sociales ha supuesto un gran cambio para la comunicación corporativa. Se ha pasado de una comunicación unidireccional, basada en los clásicos medios de comunicación de masas, a un modelo bidireccional en el que los usuarios hablan colectivamente y donde se reducen de manera considerable las limitaciones temporales y geográficas. De esta forma, el papel del receptor tradicional ha sufrido una gran evolución, ha pasado de ser un simple consumidor de contenidos a crearlos, editarlos y distribuirlos en su comunidad en función de sus gustos e intereses.

2. Twitter se ha consolidado como uno de los principales medios de comunicación externa en las organizaciones.

3. La comunicación corporativa es eficaz cuando se conoce al público objetivo al que se dirige una institución. Las organizaciones no necesitan estar presentes en todas las redes sociales, sino que deben centrar sus esfuerzos en aquellas en las que esté presente el sector de la población al que se quieren dirigir.

4. El perfil de una institución en Twitter es su carta de presentación. Por tanto, debe estar muy cuidado. En él se deben plasmar los valores, la identidad y la personalidad corporativa, de manera que sea fácilmente reconocible para los usuarios.

5. La función de comunicación en las organizaciones debe ser realizada por un profesional, que se encargue de elaborar un plan de acción en el que se marquen los objetivos y las pautas que se van a desarrollar. Seis puntos son imprescindibles en todo plan de acción: ¿Cuáles son los objetivos? ¿Qué decir? ¿Cómo decirlo? ¿Cuándo decirlo? ¿Quién lo dice? ¿Cómo evaluar los resultados?

6. La repercusión e importancia de una cuenta corporativa en Twitter va a depender de su gestión. La institución debe comunicarse de manera constante y activa con su público; solo así podrá encontrar una voz propia, es decir, establecer una identidad única que la distinga del resto. Para ello es muy importante escuchar a los usuarios y actuar sobre esa base: escribiendo tuits que aporten valor, generando conversación, contestando a las preguntas y retuiteando los contenidos de otros usuarios se conseguirá que los seguidores hablen de la institución de manera positiva.

7. Para que la cuenta adquiera notoriedad, es interesante llevar a cabo acciones que únicamente se desarrollen a través de Twitter.

En el caso de la comunicación corporativa, la cantidad de seguidores de una cuenta perteneciente a una institución no es el valor más relevante para medir su impacto. Parámetros como el número de tuits, las menciones, los clics, los retuits, los leads, las respuestas, los hashtags o las listas a las que se pertenece ayudan a evaluar la repercusión de las cuentas corporativas en Twitter.

\section{4}




\section{Referencias}

1. Álvarez, G. \& Palma, R.J. (2011, 1 de septiembre). Análisis de la influencia en Twitter. Las métricas que revelan la influencia de los tuiteros. Recuperado el 15 de abril de 2014, de IDG: http://www.idg.es/pcworldtech/ mostrarArticulo.asp?id=206266\&seccion=pymes

2. Carracosa, J.L. (1992). Una comunicación eficaz para el éxito en los negocios. Madrid, España: Ciencias de la dirección.

3. Castelló, A. (2010). Una nueva figura profesional: el Community Manager. Revista Pangea (4), 74-97.

4. Castells, M. (2009). Comunicación y poder. Madrid, España: Alianza editorial.

5. Castillo, A. (2008, julio). La comunicación empresarial en Internet. Revista Icono14: revista de comunicación y nuevas tecnologías, (11), 1-18. Recuperado el 29 de abril 2014, de http://www.icono14.net/ojs/index. php/icono14/article/viewFile/348/225

6. Cink Shaking Business (2011). Observatorio sobre uso de las redes sociales en la Pymes españolas. Fundación Banesto.

7. Fernández, M. (2011). Comunicación y reputación en empresas e instituciones. Experiencias profesionales y propuestas prácticas. Madrid, España: Editorial Universitas.

8. Fundación Orange (2012). eEspaña. Informe 2012 sobre el desarrollo de la sociedad de la información en España. Madrid, España. Recuperado el 15 de abril de 2014, de http://www.proyectosfundacionorange. es/docs/eE2012.pdf

9. Gámez, A. (2013, 21 de enero). Uso racional de las métricas en Twitter. Marketing online. Recuperado el 25 de marzo de 2014, del blog de agamazcm: de http://www.agamezcm.com/2013/01/metricas-en-twitteruso-y-calculo-por-community-manager.html\#ixzz2OaDrdsCT.

10. Garrido, F.J. (2008). Comunicación de la estrategia. La efectividad está en la dirección. Barcelona, España: Ediciones Deusto. Planeta de Agostini Profesional y Formación S.L.

11. Gil, J.M. (2013, 19 de marzo). Curso Twitter Marketing para empresas y profesionales. Estrategias de Marketing Online. Recuperado el 20 de marzo de 2014, de http://www.estrategiasdemarketingonline. com/twittermarketing/video1-2/?setuser=1198

12. Gonzalo, M. (coord.). Acevedo, I.; Jiménez, F.; Paván, B. \& Velasco, J.J. (2012). Las mejores prácticas en redes sociales para empresas: guía y casos de éxito: Hipertextual.

13. Hernández, R.M. (1991). La imagen de las empresas. Cáceres, España: Universidad de Extremadura.

14. Instituto Nacional de Estadística (2012, 3 de octubre). Encuesta sobre Equipamiento y Uso de tecnologías de la información y comunicación en los hogares. Recuperado el 17 de enero de 2014, del sitio web de INE: http://www.ine.es/jaxi/menu.do?type=pcaxis\&path=\%2Ft25\%2Fp450\&file=inebase\&L=0

15. Kappler, J.T. (1963). The science of human communication. Nueva York, Estados Unidos: Basic book.

16. Lázaro, M. (2012, 22 de enero). 7 Herramientas gratuitas para medir la influencia en Twitter de tu marca o empresa. Recuperado el 20 de marzo 2014, del blog Hablando en corto: http://hablandoencorto. blogspot. com.es/2012/01/medir-influencia-twitter.html 
17. Martín, F. (2004). Diccionario de comunicación corporativa e institucional y relaciones públicas. Madrid, España: Fragua.

18. Territorio Creativo (2012). Manual de uso Twitter. Madrid. Recuperado el 19 de febrero de 2014, de http:// www.territoriocreativo.es/downloader?file=2012/01/Tc_manual_Twitter.pdf

19. Vargas, E. (2011, 12 de mayo). 10 prácticas que los medios deben evitar en Twitter. Manual de estilo. Recuperado el 20 de febrero de 2014, del sitio web de la Fundéu BBVA: http://www. manualdeestilo.com/ escribir/10-practicas-que-los-medios-deben-evitar-en-twitter

20. Vaughan, P. (2012, 21 de marzo). Everything You Need to Measure Twitter Marketing ROI. Recuperado el 26 de marzo de 2013, del blog Hubspot: http://blog.hubspot.com/blog/tabid/6307/bid/31963/EverythingYou-Need-to-Measure-Twitter-Marketing-ROI.aspx

21. Wolf, M. (1996). La investigación de la comunicación de masas. Crítica y perspectivas. Barcelona, España: Paidós. 